\title{
JUDICIALIZAÇÃO DA SAÚDE EM FACE DA INEFICIÊNCIA DO SISTEMA ÚNICO DE SAÚDE - SUS
}

\author{
HEALTH JUDICIALIZATION DUE TO THE INEFFICIENCY OF THE \\ UNIQUE HEALTH SYSTEM - SUS
}

\author{
Renata Beatriz Bilego ${ }^{1}$ \\ Fabiane Alves da Silva² \\ Mauro Luis de Melo 3
}

\begin{abstract}
RESUMO: Em tempos de grandes transformações sociais, é possível perceber o surgimento de doenças e a necessidade de novos tratamentos na área de saúde. Todavia, nem sempre as demandas sociais coadunam com a velocidade de edição de normas a respeito das políticas públicas que devem ser prestadas pelo Estado no que tange à saúde. Por essa razão, o objetivo da pesquisa é investigar em que medida a criação de normas voltadas à saúde no Brasil diminuiria o número de demandas judiciais para a aquisição de medicamentos e tratamentos específicos, ainda não regulamentados pelo Sistema Único de Saúde (SUS). Evitando, assim, a judicialização da saúde. Para tanto, recorreu-se a uma pesquisa de natureza básica, ante a inevitabilidade de se apresentar conceitos específicos, bem como da necessidade de se esclarecer a respeito da implantação do Sistema Único de Saúde. Nesse viés, a utilização da técnica de pesquisa bibliográfica foi fundamental para destacar a atuação do Estado no fornecimento de saúde por meio de suas políticas públicas. Desta maneira, pode-se constatar que a organização do sistema de implantação de políticas públicas é bastante falha, ou seja, o Estado não consegue acompanhar efetivamente a demanda de solicitações ante a judicialização da saúde. Posto isso, pode-se concluir que, apesar de falho, o sistema de implantação de novas políticas públicas visa abranger as necessidades que surgem,
\end{abstract}

\footnotetext{
${ }^{1}$ Advogada especializada na área cível, Especialista em Docência do Ensino Superior pelo Centro Universitário Unicathedral e Docente do Curso de Administração, Superior em Gestão Pública, Superior em Recursos Humanos do Centro Universitário Cathedral - Unicathedral.

2 Graduada em Letras Português e Literatura Portuguesa pela Universidade Federal de Mato Grosso (UFMT); Graduada em Espanhol - Apostilamento - UFMT/PARFOR; Graduada em Pedagogia pelo Instituto Superior de Educação Ibituruna Especialização em Gêneros Textuais na Escola, pela UFMT; Docente da Rede Estadual de Mato Grosso. Docente do Curso de Pedagogia, Superior em Gestão Comercial, Superior em Recursos Humanos no Centro Universitário Cathedral - UniCathedral.

3 Formado em Administração pelo Centro Universitário Unicathedral, Especialista em gestão empresarial e controladoria, funcionário da Caixa Econômica Federal e docente do Curso de Administração, Superior em Gestão Pública, Superior em Recursos Humanos do Centro Universitário Cathedral - Unicathedral.
} 
e o poder judiciário caminha junto ao Governo, no sentido de achar soluções para as demandas existentes, de modo a encontrar um equilíbrio entre as necessidades presentes e o surgimento demandas.

PALAVRAS CHAVE: Direito à saúde. Sistema Único de Saúde. Políticas Públicas. Judicialização.

ABSTRACT: In times of great social changes, it is possible to perceive the appearance of diseases and the demand for new treatments in the health area. However, social demands are not always aligned with the speed of editing standards regarding public policies that must be provided by the State with regard to health. For this reason, the present work research aims to investigate the extent to which the creation of health standards in Brazil would decrease the number of lawsuits for the purchase of specific drugs and treatments, not yet regulated by the Brazilian Unified Health System (SUS). Thus, avoiding the judicialization of health. For this purpose, a basic research was employed, given the inevitability of presenting specific concepts, as well as the need to clarify about the implementation of the Unified Health System. In this regard, the use of the bibliographic research technique was fundamental to highlight the State's role in providing health care through its public policies. In this way, it can be seen that the organization of the public policy implementation system is quite flawed, showing that the State is unable to effectively monitor the demand for requests before the judicialization of health. Thus, it can be concluded that, although flawed, the system for implementing new public policies aims to cover the needs that arise and the judiciary moves with the Government, in order to find solutions to existing demands and a balance between present needs and arising demands.

KEYWORDS: Right to health. Brazilian Unified Health System. Public policy. Judicialization. 


\section{INTRODUÇÃO}

Desde os primórdios dos tempos, o homem busca qualidade de vida. Os anseios de viver longamente faz com que o homem, em sua maioria, tenha como primordial os cuidados com sua saúde. Acontece que cuidar do bem estar, da qualidade de vida e principalmente da saúde, não é de certa forma uma prerrogativa única e exclusiva do indivíduo. É, também, dever do Estado. Assim, o direito à saúde é um direito fundamental social dado ao indivíduo e garantido pela Constituição Federal brasileira, devendo o Estado proporcionar políticas públicas na área da saúde a todos.

Ocorre que, mesmo sendo assegurado como um direito fundamental social, a garantia à saúde não vem sendo prestada conforme preceitua a Constituição Federal. Em alguns aspectos, seu fornecimento se caracteriza como calamitoso, sendo ineficaz para atender, inclusive, as demandas mais básicas do indivíduo.

O que tem ocorrido, é que com a evolução da sociedade, houve um grande aumento de algumas doenças e o surgimento de uma porção de novos diagnósticos, com a ampliação de doenças raras, o que tem dificultado ao Estado manter um cuidado adequado com o indivíduo. Ou seja, para fornecer o tratamento e medicamento adequado, por vezes é necessária à descoberta de novos medicamentos e tratamentos, ou até mesmo, há a necessidade de pesquisa para verificar se é possível utilizar medicamentos já existentes, situação que leva certo tempo para ser regulamentada.

Por essa razão, a busca por assistência à saúde, de um modo geral, e de medicamentos tem aumentado significativamente, e as políticas públicas previstas na área da saúde não têm conseguido suprir a demanda.

E é sob esse aspecto que se destaca a importância da pesquisa. Assim, ela se justifica uma vez que é fundamental entender a respeito da necessidade de novas regulamentações na área da saúde no Brasil, de modo a preservar os direitos 
sociais fundamentais determinados pela Constituição Federal frente às novas demandas da sociedade.

Desse modo, com o propósito de compreender os empecilhos para garantir o direito à saúde, surge o problema: em que medida uma nova normatização na saúde do Brasil diminuiria o número de demandas judiciais para a aquisição de medicamentos e tratamentos específicos, ainda não regulamentados pelo Sistema Único de Saúde?

Assim, é importante a demonstração do trabalho exercido pelo Ministério da Saúde junto ao poder judiciário brasileiro em busca de tentar garantir a todos esse direito fundamental.

O desenvolvimento do trabalho realizou-se por meio de uma pesquisa de natureza básica, ante a necessidade de esclarecimentos acerca da evolução social e o surgimento de doenças e a indigência de novos tratamentos, bem como análise de descrição do direito constitucional do direito à saúde.

Realizou-se uma pesquisa bibliográfica, no escopo de consolidar o conceito de judicialização, além de pesquisas em sites, revistas e periódicos do Governo Federal, com o intuito de entender quais são as regras atuais do Sistema Único de Saúde - SUS e quais são os pontos que ainda devem ser ajustados com o objetivo de evitar a judicialização, no intento de formular as respostas ao problema levantado.

Quanto a abordagem, o método dedutivo se fez eficaz, ante a análise dos dispositivos gerais da Constituição Federal, no que tange ao direito à saúde e, ainda, descrevendo particularidades sobre o Sistema Único de Saúde por meio das normas mais específicas sobre o assunto.

Ademais, por ser a saúde um direito fundamental e sua má prestação interferir de forma direta na vida do cidadão brasileiro é que se fazem necessárias uma investigação e análise a respeito dos parâmetros que justifiquem e legitimem a atuação judicial no campo das políticas públicas. 


\title{
2 DIREITO CONSTITUCIONAL À SAÚDE
}

A saúde é um princípio básico do indivíduo. Sua proteção e a sua necessidade encontram fundamento na Declaração Universal dos Direitos Humanos, cujas regras incorporam a saúde aos demais direitos fundamentais inerentes à dignidade humana.

Em seu artigo jurídico Direito a saúde e o princípio da reserva do possível, Leny Pereira da Silva citando Zanobini relata:

\begin{abstract}
Nenhum bem da vida apresenta tão claramente unidos o interesse individual e o interesse social, como o da saúde, ou seja, do bem-estar físico que provém da perfeita harmonia de todos os elementos que constituem o seu organismo e de seu perfeito funcionamento. Para o indivíduo, saúde é pressuposto e condição indispensável de toda atividade econômica e especulativa, de todo prazer material ou intelectual. $O$ estado de doença não só constitui a negação de todos estes bens, como também representa perigo, mais ou menos próximo, para a própria existência do indivíduo e, nos casos mais graves, a causa determinante da morte. Para o corpo social a saúde de seus componentes é condição indispensável de sua conservação, da defesa interna e externa, do bem-estar geral, de todo progresso material, moral e político. (SILVA, 2016, p. $6)$.
\end{abstract}

A saúde é um bem fundamental. Sem saúde o indivíduo não pode gozar inclusive de outros direitos fundamentais inerentes aos seres humanos, por isso é considerada como um bem indispensável ao indivíduo.

Segundo Pedro Lenza (2012, p. 1077), "a saúde é direito de todos, dever do Estado, garantido mediante políticas sociais e econômicas que visem à redução do risco de doenças e de outros agravos e ao acesso universal e igualitário às ações e serviços para sua promoção, proteção e recuperação".

Já pelo preceito constitucional, é possível verificar a amplitude desse direito, que não tem como escopo apenas o fornecimento de assistência hospitalar, mas também destaca a função do Estado e o seu dever de proporcionar melhorias e 
qualidade de vida aos seus membros, sugerindo ações por meio de políticas públicas que possam educar o cidadão e reduzir riscos e doenças.

Assim, de acordo com o texto constitucional, em seu art. 196:

Art. 196. A saúde é direito de todos e dever do Estado, garantido mediante políticas sociais e econômicas que visem à redução do risco de doença e de outros agravos e ao acesso universal e igualitário às ações e serviços para sua promoção, proteção e recuperação. (BRASIL, 1988).

O que se verifica é que as ações voltadas à saúde de certo modo, dependem do desenvolvimento do Estado, levando-se em consideração os aspectos sociais e culturais para a sua fomentação.

\section{POLÍTICAS PÚBLICAS}

No escopo de atender o interesse público dos membros do Estado, é que são constituídas as políticas públicas. Elas são erigidas em face do ambiente sociopolítico e econômico da sociedade.

O dever de implantá-las é da administração Pública e dos interessados em promovê-las, com base nos problemas sociais encontrados.

Assim, políticas públicas têm por função "Promover orientações normativas, guiadas por valores e por finalidades, para a elaboração de estratégias, programas e planos que procuram adequar meios para atingir determinados fins" (PROCOPIUCK, 2013, p. 139).

As Políticas Públicas são a materialização das atividades estatais no que tange a prestação do bem estar social, com a destinação de recursos específicos para a resolução de dificuldades coletivas enfrentadas pelos indivíduos.

Ao instituí-las, deve-se observar, desde ideias e valores sociais, aos aspectos econômicos do Estado. Ela, então, tornar-se-á eficaz e aplicável quando definir normas e regras que pautarão os comportamentos do indivíduo, seja de forma individual ou coletiva, visando à melhoria na qualidade de vida. 


\section{ATUAÇÃO DO SISTEMA ÚNICO DE SAÚDE (SUS)}

Foi ante a necessidade de proporcionar qualidade vida, observando os preceitos gerais e estabelecer regras a respeito da implantação de políticas públicas, que foi criado o Sistema Único de Saúde (SUS), sendo consolidado por meio da Lei 8.080/90, a qual dispõe sobre as condições para a promoção, proteção e recuperação da saúde, a organização e o funcionamento dos serviços correspondentes, além de outras providências.

No que tange ao direito à saúde, a referida lei, logo em suas disposições gerais, descreve que:

Art. $2^{\circ}$ A saúde é um direito fundamental do ser humano, devendo o Estado prover as condições indispensáveis ao seu pleno exercício.

$\S 1^{\circ} \mathrm{O}$ dever do Estado de garantir a saúde consiste na formulação e execução de políticas econômicas e sociais que visem à redução de riscos de doenças e de outros agravos e no estabelecimento de condições que assegurem acesso universal e igualitário às ações e aos serviços para a sua promoção, proteção e recuperação. (BRASIL, 1990).

Quando se trata de saúde, principalmente em seus aspectos sociais, é imperioso destacar que a saúde é o bem mais precioso do indivíduo e sua atenção é um direito de todos os cidadãos.

A lei que instituiu o Sistema Único de Saúde (SUS), em seu texto, ainda preleciona que:

Art. $4^{\circ} \mathrm{O}$ conjunto de ações e serviços de saúde, prestados por órgãos e instituições públicas federais, estaduais e municipais, da Administração direta e indireta e das fundações mantidas pelo Poder Público, constitui o Sistema Único de Saúde (SUS). (Ibidem). 
Assim, a criação do Sistema Único de Saúde (SUS) está diretamente ligada ao dever e a responsabilidade do Estado em sopesar o direito à saúde, proporcionando a sua efetivação entre os indivíduos.

Por essa razão, a lei 8.080/90 foi criada para efetivar a tutela do Estado com relação ao indivíduo, criando regras e controle do fornecimento dos serviços de saúde, de modo a proporcionar uma atuação igualitária em todo o território nacional.

A função do Sistema Único de Saúde é a de gerir as ações e os serviços de saúde prestados pelos entes da federação, buscando um equilíbrio no fornecimento de saúde, especificando o dever e a atuação de cada um na construção do sistema.

Assim, os princípios que fundamentam as atividades do Sistema Único de Saúde (SUS) são essenciais para a compreensão da organização e fornecimento dos serviços. De tal modo, a universalização da saúde assegura que este seja um direito de todos, bem como a equidade, que se destaca com o objetivo de diminuir as desigualdades, além da integralidade que percebe e considera a pessoa como um todo ante as suas necessidades mais básicas, visando à qualidade de vida da pessoa.

A lei atribui à União o dever de financiar o funcionamento da rede pública de saúde, ante ao seu dever constitucional, devendo criar as políticas públicas necessárias. Ao Estado, a lei preceitua a criação de secretarias específicas para a implantação de ações de gestão e ações voltadas à saúde e, por fim, aos municípios foi permitido organizar suas próprias atividades, executando suas ações na área da saúde.

Deste modo, ao analisar brevemente a lei $8.080 / 90$, verifica-se que uma grande quantidade de ações foi prevista com o escopo de fornecer desde a assistência básica, até alguns tratamentos mais específicos. Porém, o que se percebe nos dias atuais, é que mesmo com a referida Lei, o fluxo de pedidos de assistência à saúde não consegue acompanhar as novas demandas. 


\section{JUDICIALIZAÇÃO DA SAÚDE EM FACE DA INEFICIÊNCIA DO SISTEMA ÚNICO DE SAÚDE - SUS}

Observa-se que, mesmo com um conjunto de leis de proteção, regulamentação e fiscalização, no que tange ao fornecimento adequado de assistência da saúde, o Estado não tem conseguido suprir a demanda no atendimento do cidadão, ora por falta de recurso, ora por não haver a previsibilidade da solicitação (seja em medicamento ou tratamento), junto ao Sistema Único de Saúde.

Por esse motivo, surgem os entraves judiciais, ou seja, é direito do cidadão o acesso à saúde, como garantia de direito social fundamental, previsto pela Constituição Federal, mas a ineficiência do Sistema Único de Saúde (SUS), quanto ao planejamento e orçamento, não permite que o atendimento seja eficaz.

Insta salientar, que o Estado se adequa para fornecer a maior quantidade de medicamentos, tratamentos e procedimentos possíveis. Todavia, existem algumas enfermidades que fogem dos padrões epidemiológicos previstos.

Em face dessa desorganização e das necessidades específicas é que o indivíduo recorre ao Poder Judiciário. É o momento em que se transfere para o juiz de direito a responsabilidade de deliberar sobre políticas públicas de saúde.

Assim, muitos questionamentos surgem, colocando em dúvida quanto ao limite da interferência do Poder Judiciário nas questões de saúde, principalmente nos recursos públicos aplicáveis nessa área.

Todavia, antes de discorrer a respeito da participação do poder judiciário nas decisões de fornecimento de medicamentos e imposições de novos tratamentos é imperioso compreender o que é a judicialização.

Mansur define judicialização como sendo:

Um fenômeno mundial por meio do qual importantes questões políticas, sociais e morais são resolvidas pelo Poder Judiciário ao invés de serem solucionadas pelo poder competente, seja este o Executivo ou o Legislativo. Assim, o fenômeno da judicialização significa levar ao conhecimento do Judiciário a 
matéria que não foi resolvida, como deveria, pelo Poder Executivo ou pelo Poder Legislativo. (MANSUR, 2016).

Verifica-se, então, a utilização do poder judiciário para resolver problemas que não são resolvidos pelo Sistema Único de Saúde (SUS).

Em linhas gerais significa que, ante a impossibilidade de atender as demandas do indivíduo por meio de suas políticas públicas, o Estado permite, mesmo que involuntariamente, a interferência do Poder Judiciário na tomada de suas decisões, impondo condições quanto ao fornecimento de assistência à saúde do indivíduo.

O tema é amplamente discutido, e Andre de Carvalho Ramos pondera que:

No Supremo Tribunal Federal, há precedentes que autorizam a intervenção do poder judiciário, exigindo do poder executivo à adoção de providencias administrativas que visem à melhoria da qualidade da prestação de serviços a saúde pública. Houve a ponderação entre os princípios do "mínimo existencial" e da reserva do possível, tendo sido decidido que no caso da saúde, a intervenção judicial é possível, pois não há usurpação na separação de poderes, mas tão somente determinação judicial para que o "poder executivo cumpra política pública previamente estabelecida" - RE 642.536 - AgR, Rel. Min. Luiz Fux, julgamento em 5-2-2013, Primeira Turma, DJE de 27-22013. (RAMOS, 2017, p. 67).

O ponto controverso é que os juízes de direito, no uso de suas atribuições, não participam ativamente da criação das políticas públicas relacionadas à saúde, o que prejudica o sistema com a sua tomada de decisão, ou seja, o magistrado pode deferir pedido de assistência a tratamento ou fornecimento de medicamentos que não estão previstos pelo Sistema Único de Saúde, o que faz com que parte dos recursos que seriam destinados a outros tratamentos sejam direcionados a um paciente específico, que formulou pedido na justiça com fundamento no direito à saúde, previsto pela Constituição Federal.

É como se, com a judicialização da saúde o poder judiciário concedesse um tratamento a um paciente, podendo de certo modo prejudicar o tratamento de outro por falta de recursos, uma vez que este foi alocado em um tratamento que não estava previsto. 
Embora, a judicialização da saúde pareça causar um desequilíbrio no fornecimento e assistência à saúde, esta tem como escopo assegurar direitos. O poder judiciário atua somente face da ineficiência do Governo em cumprir com suas funções.

Sobre a judicialização da saúde, Luiz Felipe Conde preleciona:

Não pode se negar que a Justiça é, de fato, um instrumento legítimo de acesso à saúde e premissa elementar de uma democracia. Se de um lado há a esperança da busca por procedimentos, medicamentos e outros serviços, do outro está a dificuldade de se fazer previsões orçamentárias e distribuição dos recursos por parte dos gestores nas diferentes esferas da saúde, ameaçando sua sustentabilidade econômico-financeira. (CONDE, 2019).

A Constituição Federal prescreve que o direito à saúde deve ser exercido de forma universal, igualitária e gratuita, ou seja, a lei maior não pondera a respeito de que a saúde seria ofertada na medida em que se estabelecem as políticas públicas e, é por essa razão, que há a possibilidade da judicialização da saúde.

\section{CONSIDERAÇÕES FINAIS}

A ideia basilar da pesquisa teve como escopo proporcionar uma investigação ante a necessidade de criação de normas voltadas à saúde no Brasil, e como estas diminuiriam o número de demandas judiciais para a aquisição de medicamentos e tratamentos específicos ainda não regulamentados pelo Sistema Único de Saúde evitando, assim, a judicialização da saúde.

Todavia, o estudo proporcionou uma reflexão a respeito da judicialização da saúde em face da ineficiência dos atendimentos previstos pelo Sistema Único de Saúde (SUS).

Sendo assim, pode-se verificar que o assunto é demasiadamente necessário de ser estudado, umas vez que, a edição de novas normas e a concessão de 
assistência à saúde interfere diretamente nos direitos sociais do indivíduo previsto pela Constituição Federal.

Pode-se notar que os problemas vivenciados pela judicialização da saúde têm como foco uma necessidade específica de um indivíduo e não, necessariamente, a edição de novas normas propriamente ditas.

Ou seja, é um indivíduo particular, que em razão de enfermidade específica, vê-se desassistido e, na maioria das vezes, judicializa pedido de assistência à saúde.

Ocorre que, quando se trata de políticas de implantação de regras quanto à regulamentação e fornecimento de tratamentos e medicamentos, leva-se em consideração o coletivo. Ou seja, o Sistema Único de Saúde (SUS), ao fixar as regras de atendimento à saúde observa as transformações da sociedade atual, instituindo as necessidades gerais.

O controverso ora analisado, se fixa em dois pontos, sendo: o Sistema Único de Saúde (SUS) não consegue prever as mudanças que podem ser sofridas no organismo do indivíduo, editar normas para assistência imediata e, ainda, não se sabe ao certo como se devem ocorrer os atendimentos das demandas de assistência à saúde por meio da judicialização.

O Sistema Único de Saúde (SUS) trabalha com um período de tempo específico determinado pela lei para a revisão de seus procedimentos e edição de novas normas. Desse modo, a cada período, o Ministério da Saúde deve se ater as novas necessidades da sociedade ao fixar e estabelecer as novas políticas, destinando verbas adequadas para tratamentos e fornecimentos de medicamentos.

Advém que, mesmo assim, quando o Sistema Único de Saúde (SUS) não prevê a demanda de assistência, o indivíduo por meio de seu Direito Constitucional faz-se pleito na justiça a fim de ter o seu direito garantido.

Percebe-se que a busca pela justiça é algo recorrente na sociedade. O fato que deve ser verificado sempre que houver uma nova propositura de ação judicial na área da saúde é observar se o direito individual de um cidadão, não irá se sobrepor aos direitos coletivos.

Com base nisso, Governo e Poder Judiciário buscam meios de encontrar um equilíbrio ante as falhas do sistema. Membros do Governo reclamam que a 
judicialização da saúde prejudica o equilíbrio entre as partes, uma vez que, quando um indivíduo reclama judicialmente por assistência, partes dos recursos são destinadas a atender apenas a necessidade deste indivíduo, o que prejudicaria a sociedade como um todo.

Ademais, o Governo pondera que quando se judicializa pedido de assistência de saúde, há uma transferência de poderes, o que possibilitaria o poder judiciário de exercer um poder que não foi lhe dado, como seria o caso de instituições de políticas públicas.

O que se nota é que o problema é cíclico, ou seja, com a sociedade em plena evolução, novos casos de doenças e necessidade de tratamentos e fornecimentos de medicamentos serão sempre necessários. Todavia, o Governo, por meio de suas ações, não consegue acompanhar as novas demandas, fazendo com que o Poder judiciário tenha que atuar numa competência que não seria sua, frente ao fundamento do direito à saúde ser um direito constitucional.

Portanto, conclui-se que é necessário readequar o sistema de fornecimento de saúde para que o acesso a tratamentos e medicamentos não necessitem mais ser judicializados. O equilíbrio entre fornecer para um ou para todos deve ser a regra. Não há que se fazer distinção entre os indivíduos, mas a legislação do Sistema Único de Saúde (SUS) deve prever situações em que haja a necessidade de novos tratamentos. 


\section{REFERÊNCIAS BIBLIOGRÁFICAS}

BRASIL. Constituição (1988). Constituição da República Federativa do Brasil. Brasília: Senado, 1988.

BRASIL. Lei $n^{\circ}$ 8.080, de 19 de setembro de 1990. Diário Oficial da União. Brasília, DF, 19 de setembro de 1990.

CONDE, Luis Felipe. A crescente judicialização e aumento da influência do Judiciário no sistema de saúde. In: Revista Consultor Jurídico. 18 dez. 2019. Disponível em: https://www.conjur.com.br/2019-dez-18/judicializacao-influencia-judiciario-sistema-saude. Acesso em 11 mar. 2020.

LENZA, Pedro. Direito Constitucional esquematizado. 16. ed. São Paulo: Saraiva, 2012.

MANSUR, Sâmea Luz. O Fenômeno da Judicialização na Sociedade Contemporânea: breves apontamentos sobre o termo "Judicialização", frequentemente citado em informativos do STF e STJ. 2016. Jusbrasil. Disponível em: <https://samealuz.jusbrasil.com.br/ artigos/389418859/ofenomeno-da-judicializacao-na-sociedade-contemporanea>. Acesso em: 10 mar. 2020.

PROCOPIUCK, Mario. Políticas públicas e fundamentos da administração pública: análise e avaliação, governança e redes de políticas, administração judiciária. São Paulo: Atlas, 2013.

RAMOS, André de Carvalho. Curso de Direitos Humanos. 4. ed. São Paulo: Saraiva, 2017.

SILVA, Leny Pereira da. Direito à Saúde e o Princípio da Reserva do Possível. Instituto Brasiliense de Direito Público - IDP. Curso de Graduação Lato Sensu em Direito. Brasília, DF: 2016. Disponível em: https://www.stf.jus.br/arquivo/cms/processoAudienciaPublicaSaude/ anexo/ DIREITO_A_SAUDE_por_Leny.pdf. Acesso em 05 mar. 2020. 